\title{
Guidance on consultant posts in general psychiatry for regional advisers
}

\section{Designation of post \\ Introduction}

General psychiatry is a broad category where psychiatrists are involved in the assessment and treatment of a wide variety of patients and problems in a wide variety of settings. They may be based in general hospital, psychiatric hospitals or academic departments. They will work both in hospital and community settings, providing in, day and out-patient care. They generally work as part of a multidisciplinary team. Apart from work with the adult mentally ill, including the psychoses and neuroses, a variety of specialist services for particular problems come within this category. It should include liaison psychiatry, neuropsychiatry, eating disorders, sexual disorders, behavioural psychotherapy, psychopharmacology, epidemiology, and so on.

The consultant post may be concerned entirely with adult general psychiatry and the sessional programme will then indicate that duties will be concerned with the provision of psychiatric care for the whole range of psychiatric disorders in a variety of hospital and community settings.

Whenever a post is designated as having special interest or special responsibility, the relevant duties and supporting facilities should be described separately from those of general psychiatry in order to ensure that the service demands and supporting facilities with reference to each are appropriate.

A special interest post may include a special clinical interest for a few service sessions per week. Such a commitment does not signify exclusive responsibility for a specialist service and in some cases it may be shared with other consultants. The resources which it attracts will vary according to specific circumstances.

A special responsibility post will involve the organisation and provision of a specialised service in parallel with major duties in general psychiatry. Such a post will attract candidates who have substantial higher-training experience in both general psychiatry and in the special interest subject itself. It is particularly important in posts of this kind, where there is to be more than one type of clinical responsibility, that allocation of time and resource provision should be unambiguous. The sessional distribution between general psychiatry and special clinical interest may vary from one situation to another, but the provision of supporting resources should be appropriate pro rata.

\section{Other consultant staff}

Details should be available concerning consultant provision for the adult general psychiatry service throughout the Health District.

Details should be available concerning consultant provision for other psychiatric services throughout the Health District and, where appropriate, the links with Regional Sub-specialities.

It should be made quite clear how the post in question will contribute to the care of various population sub-groups such as the elderly.

\section{Population}

Total size, numbers of those over 65 years, and any other relevant specific age group depending upon a proposed special interest or other circumstances. It is also desirable to have information with regard to other demographic population data such as social class distribution, numbers living alone or in city centre environments which may be relevant to the clinical load of the post in question.

Mention should be made of any specific geographic problem such as travelling time when distances are considerable.

Overall consultant/population ratios for the Health District should be specified. These should be evaluated with reference to 'Calculating a district's psychiatric manpower' (Watson, 1986).

If clinical duties are to be sectorised, then details concerning the size of the relevant sector population are required.

The way in which clinical duties are to be shared with other consultants throughout the District should be specified, as well as within a sector if this is relevant.

Any special arrangement across Health District boundaries for the provision of clinical care of special patient groups needs to be mentioned.

It should be specified that two sessions should be available for the development of an area of interest. The choice of interest may be left open or may be specified depending upon the needs of the service. It is quite likely that this interest may change over a period of time.

\section{Emergency on-call arrangements}

The consultant will clearly need to play a part in the consultant rota for emergency on-call work and it 
is useful to have details of the proposed frequency during weekdays and weekends, as well as the population covered.

\section{Clinical facilities}

\section{Current provision}

The style of clinical service which is proposed may of course vary considerably from one situation to another, perhaps with differing degrees of emphasis on hospital and community based facilities. Nevertheless each consultant in general psychiatry requires adequate direct access to a range of resources and the proposed way in which existing facilities will be shared needs to be made quite clear. Such details should be provided with regard to in-patient beds as well as day patient and out-patient facilities.

\section{Projected developments}

It is always very useful to have details of any service developments which may be envisaged. Where there is a serious current deficiency in resource provision it is particularly important to have a statement that plans are well laid by the relevant authority so that the deficiencies will be rectified in the near future. $A$ statement should be made as to whether or not there are specific resources available to the development of an area of interest. If no such resources are available, a statement should be made as to the prospect of their becoming available.

\section{Research}

If the job description suggests that sessional time will be made available for research, then the clinical load should be compatible with this and support facilities must be adequate to render it a feasible proposition.

\section{Supporting staff and other facilities}

A consultant in general adult psychiatry may reasonable expect to work closely with a clearly identified multidisciplinary clinical team which can provide support which is adequate and appropriate to the size of the clinical practice envisaged. The team would normally consist of non-consultant medical staff together with colleagues in social work, clinical psychology, occupational therapy and nursing staff, including community psychiatric nurses. There also needs to be adequate provision of secretarial help, particularly when there is likely to be a considerable amount of administration involved, as in the development of community facilities which require liaison with several other agencies. The consultant would also reasonably expect to be provided with unshared appropriately equipped office space in at least one main clinical base.

\section{Approved by the Court of Electors April 1991}

\section{Reference}

WATsON, J. P. (1986) Calculating a district's psychiatric manpower. Bulletin of the Royal College of Psychiatrists, 10, 334-337.

\section{General practice funding: the scope of the hospital element}

\section{Recent Circular from the NHS Management Executive}

The College has been informed that all mental health referrals will be charged to GP budget holders from April 1993. However, the College continues to be concerned over the issue of psychiatric referrals in relation to GP fund-holding, in particular the anomaly whereby there is to be a charge through the GP budget for referrals to consultant psychiatrists and occupational therapists but not to other members of the mental health team.

We have received an explanation from the Management Executive as to why this decision was made. They appreciate the difficulties which will arise if GPs alter fundamentally their referrals by referring patients to CPNs who would then, if necessary, refer on to the consultant (in which event it would not be charged to the fund). They hope eventually to bring all mental health referrals under the scope of the scheme and FHSAs have been asked to monitor GP referral patterns to establish whether any significant change would be identified which might be due to CPNs and psychologists being regarded as a 'free good' in which case they have been asked to take up this point with the practice concerned.

I would be very grateful if any member of the College who has noticed such a change in the pattern of referrals from GPs could contact me in writing. I would like to collect evidence on this matter which can then be submitted, if necessary, to the Chief Executive of the NHS Management Executive.

Professor A. C. P. Sims

October 1991 